\title{
O PALCO DA PRAÇA: AS TRANSFORMAÇÕES NA PRAÇA FRANKLIN ROOSEVELT PELAS MÃOS DO TEATRO
}

\author{
Celina Cardoso
}

\begin{abstract}
Bacharel em Comunicação Social com habilitação em Jornalismo pela Universidade Cruzeiro do Sul, com especialização em Mídia, Informação e Cultura. Há seis anos atua como assessora de imprensa junto a instituições e projetos culturais. Realizado sob orientação do Prof. Dr. Dennis de Oliveira e Prof. Moisés dos Santos
\end{abstract}

\section{Resumo}

Este trabalho discute as transformações ocorridas na praça Franklin Roosevelt, localizada no centro de São Paulo, a partir da instalação de teatros em seu entorno, bem como a ressignificação deste espaço público pela população da cidade.

Palavras-chave: cultura; urbanismo; teatro

\section{Resumen}

Este trabajo discute las transformaciones ocurridas en la plaza Franklin Roosevelt, localizada en el centro de São Paulo, a partir de la instalación de teatros por su entorno y abordar las implicaciones de este espacio público por la populación de la ciudad.

Palabras clave: cultura; urbanismo; teatro

\section{Abstract}

This essay deals about the transformations that occurred around the Praça Franklin Roosevelt in the central area of Sao Paulo after the opening of many theaters and the meaning of this city's public place.

Keywords: culture; city planning; theater 


\section{Introdução}

Localizada no centro de São Paulo, a praça Franklin Roosevelt ergue-se na paisagem da cidade na forma de um pentágono. Cobrindo a via expressa que liga as zonas leste e oeste, a construção data da década de 1970 - auge do regime militar brasileiro - época de obras faraônicas cuja função era mostrar à população o potencial e o poderio do Estado.

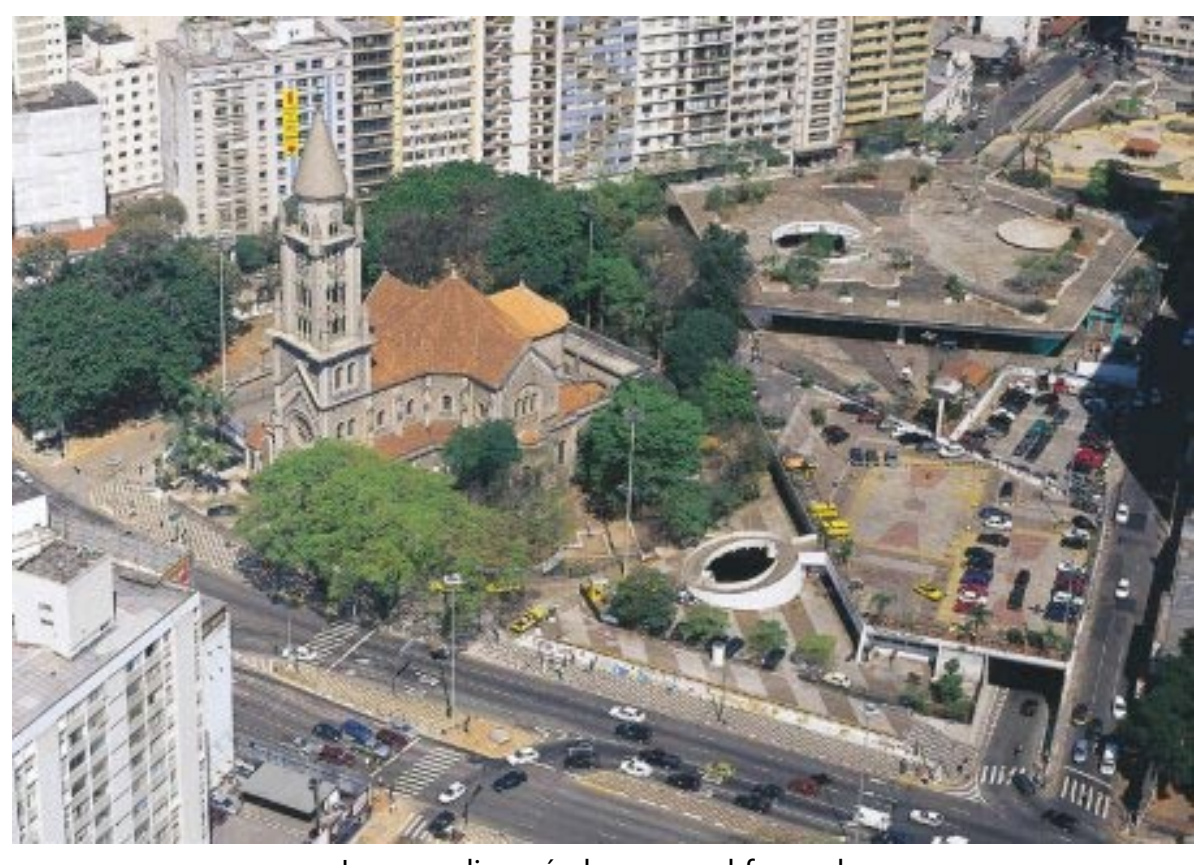

Imagem disponível em: www.hfc.com.br

A imponente estrutura não dialoga com os transeuntes, foi pensado apenas como lugar de passagem. Seus contornos não são convidativos, não promovem uma aproximação com os habitantes da cidade. Pelo contrário, provocam um distanciamento e uma sensação de estranhamento.

Essa arquitetura inóspita contribuiu para a decadência deste espaço urbano, lugar onde anteriormente fervilhava a boemia paulistana. Ali estavam bares e restaurantes, onde terminava a noite dos freqüentadores da vida cultural e noturna de São Paulo na década de 1960.

Até meados da década de 1980, a praça Roosevelt ainda conservava um certo verniz da efervescência cultural de outros tempo, ali estava o Cineclube Oscarito - pioneiro dos hoje populares noitões - onde outrora funcionou o Cine Bijou, referencia na exibição de filmes de artes na cidade em décadas anteriores. 
Todavia, o histórico cultural da praça não foi capaz de salvá-la da decadência que chegou com toda a força na década de 1990, quando o tráfico de drogas tomou conta de seu entorno e encontrou terreno fértil na galeria do segundo pavimento da Roosevelt. Até recentemente cheia de pilares e mal iluminada, o lugar oferecia os ingredientes necessários para tornar-se uma promissora "boca de fumo" e espaço de assaltos e violências. Como de fato aconteceu, a despeito do Batalhão da Polícia Militar ali presente.

Neste período de decadência e abandono, a realidade da praça era a do 'medo cotidiano'. A falta de iluminação e o aspecto inóspito da Roosevelt, acrescida dos assaltos e dos usuários de drogas que há pouco tempo atrás tinham ali 'seu' espaço na cidade afastava a população.

Essa realidade começou a mudar com a instalação de teatros no entorno da praça. As companhias teatrais passaram não só a apresentar suas montagens, mas também promoveram uma verdadeira mudança social na Roosevelt, na medida em que políticas de inclusão/aproximação começaram a ser praticadas (principalmente pela companhia "Os Satyros") junto aos grupos sociais que já estavam na praça antes da chegada dos teatros.

Os grupos de teatro instaladas ali geram hoje encontros positivos na praça Roosevelt, onde estranhos compartilham o interesse comum pela cultura teatral. Elas promovem verdadeiras ações culturais - cujo principal agente é sem dúvidas o a companhia "Os Satyros" - que conseguem mudar a relação de uma parcela dos paulistanos com a praça, gerando um comportamento civilizatório na medida em que estimulam a interação entre estranhos, que respeitam as diferenças entre si, promovendo uma nova leitura da praça Roosevelt diante da cidade de São Paulo. Esses encontros devolveram à praça seu caráter social, que cumpre com a função primeira das praças nas cidades.

Podemos dizer que antes da instalação dos teatros a praça Roosevelt era um "lugar êmico", uma estrutura cujo destino era apenas ser circundado, e, por isso vazio de significado. Sua arquitetura inóspita favoreceu ainda a leitura da praça por parte dos paulistano como um lugar público mas não-civil, uma vez que não encorajava a idéia de estabelecer-se. Este outrora "lugar êmico/não lugar" - agora é um espaço de interação/negociação entre estranhos com interesses ligados ao cotidiano da praça e das atividades culturais desenvolvidas ali.

A produção cultural instalada na praça Roosevelt serve como catalisador para que os encontros entre estranhos se deem de forma civilizada. Civilidade aqui quer dizer o encontro entre pessoas estranhas e distintas de forma que elas sejam capazes de interagir respeitando suas diferenças. Esses encontros na Roosevelt se dão pelo 
interesse comum pelas atividades culturais do lugar. Sabendo das diversas possibilidades de encontro na praça, os frequentadores exercitam a convivência com a pluralidade dos públicos que frequentam o lugar, negociando e respeitando as diferenças presentes nestes atores sociais (por isso seu caráter civilizatório).

Percebemos o despertar da consciência do "bem comum" entre os frequentadores/moradores da praça. Notamos também que a ação cultural dos teatros transformou o lugar em um centro cultural a céu aberto, totalmente integrado à cidade. Os teatros e os bares da instalados na praça espalham-se pelo seu entorno convidando os transeuntes à convivência.

Neste caso específico da praça Roosevelt, o espaço, é fator de relevância nas ações culturais que se desenvolvem aí. Inclusive, experiências vividas neste espaço contribuem para a produção cultural dos teatros da Roosevelt. Assim, o espaço ganha um novo valor e contribui para uma nova leitura/relação do habitante da cidade com seus aparelhos urbanos.

\section{Histórico}

A praça Franklin Roosevelt sempre teve vocação artística, mesmo antes de tornar-se o que é hoje. Próxima ao Teatro de Arena, ao Centro Universitário Maria Antônia e a Universidade Presbiteriana Mackenzie, o local abrigava cinemas, bares, boates e restaurantes famosos onde fervilhava a vida noturna paulistana nos anos 60 . Ali cantaram importantes nomes da música brasileira como Maysa, Elis Regina, Johnny Alf, Cauby Peixoto e César Camargo Mariano. Frequentada pela boêmia, pelos amantes das artes e pela burguesia, a praça da Consolação - como era originalmente chamada - cumpria seu papel de promoção do encontro e da interação social.

Seu papel significativo na metrópole ia de encontro ao próprio momento histórico. Em 1960, o mundo passava por mudanças culturais significativas e o surgimento de novos rumos no cenário artístico era uma das grandes evidências desse processo. Como parte da cidade pulsante, a praça da Consolação era lugar para ver as transformações acontecerem.

Oferecendo cultura e entretenimento, congregando convivência social a oportunidades de lazer, a praça dava lugar a ícones da boêmia paulistana como o restaurante "Baiúca", famoso por receber personalidades da música como a cantora Maysa; "O Farney's"; o bar "Redondo", onde atores e público do Teatro de Arena costumavam se encontrar; e o "Cine Bijou", lembrado como um dos únicos cinemas de arte da cidade de São Paulo naquele momento.

Essa movimentação somada ao contexto histórico-social conferia à praça um 
caráter prazeroso na cidade dado pela população. Graças aos signos ostentados por ela e por seu espaço, um campo aberto ao lado da igreja da Consolação. Ali era o lugar para relaxar depois do trabalho e nos finais de semana. Era o território da permanência, do convívio, do relacionar-se com a cidade e com seus habitantes.

Era um espaço civil por excelência na medida em que favorecia a ideia de utilizar este espaço público para o lazer, a convivência e o encontro.

Mas, como dissemos, eram meados de 1960 e o mundo estava mudando. E mudou. A efervescência sócio-cultural e os movimentos advindos dela não foram capazes de deter o Golpe Militar de 1964. Assim, com o novo regime vieram uma nova visão do espaço público e suas funções, afetando decisivamente a convivência pública. A medida que o novo regime tomava corpo, as grandes obras nos centros urbanos foram transformando-se na forma eficaz de lembrar o cidadão da nova gestão. As imponentes construções eram cartão de visitas do novo regime e, por isso, tinham forma imponente e inexpugnável, assim como o Regime Militar queria ser reconhecido.

Logo, o País ganhava grandes estradas e pontes e via suas praças e locais públicos transformarem-se em lugares onde a convivência e a permanência das pessoas era desencorajada nos mais amplos sentidos, começando pelo arquitetônico. Seguindo seu plano diretor urbanístico, o governo Militar deu a São Paulo o elevado Costa e Silva, um imenso viaduto ligando as zonas oeste e leste da capital paulistana.

No caminho da construção estava a praça da Consolação, por onde deveriam passar as pistas do viaduto. Então, para marcar mais uma "melhoria" no espaço público urbano, ergueu-se nesse ali um imenso pentágono dotado de galerias que mais pareciam um labirinto ao qual deram o nome de Praça Franklin Roosevelt. Essa obra foi a responsável pela gradativa decadência do espaço, cujo auge deu-se em meados de 1990.

Castrada pelo poder público, a praça Roosevelt veria seu futuro mudar a partir de 1999 com a instalação de teatros ao seu redor.

\section{A cultura enquanto significante}

Local esquecido pelo poder público e pelos habitantes da cidade de São Paulo, a praça Roosevelt teve seu destino transformado pela ação cultural desenvolvida em seu entorno por grupos teatrais que se instalaram ali. A partir dessas atividades, este espaço público passou a ter uma nova relação com a população da cidade. Relação esta que acabou conferindo um novo sentido à praça.

Se antes este espaço público detinha o sentido do medo e era ocupado por 
pessoas em situação de exclusão social (expostas a todos os problemas acarretados por ela), os teatros e as atividades culturais desenvolvidas pelas companhias passaram a dialogar com a sociedade, conferindo assim, um novo sentido a este espaço, fazendo nascer um novo território.

Dotada de uma nova dimensão simbólica, a praça Roosevelt deixou de ser o território do medo para ser o lugar da interação. Devido as atividades culturais desenvolvidas ali, pessoas de diferentes classes sociais, orientações sexuais, idades e vivências convivem de forma respeitosa em nome do interesse comum em ver a movimentação e os produtos culturais das companhias teatrais instaladas na Roosevelt. Por isso, pode-se dizer que a ação cultural desenvolvida na praça também foi civilizatória.

Esta nova forma simbólica tem um sentido amplo, pois está inserida no contexto da degradação e abandono dos centros urbanos, tanto pelo poder público, quanto pela elite - muitas vezes o leme que orienta as políticas públicas - colocando o foco sobre espaços com importante potencial sócio-cultural.

Neste sentido, a produção cultural na praça Roosevelt dialoga com o frequentador da praça na medida em que a compreensão cotidiana do significado da produção simbólica reforça as assimetrias do poder, já que as companhias teatrais instaladas no entorno da praça reproduzem as situações vividas ali. Por isso, os processos de produção simbólicas na Roosevelt têm caráter negociáveis, onde produtor e receptor negociam o sentido da obra.

A construção destes sentidos é favorecida pela relação do objeto com o público (habitantes de São Paulo e praça Roosevelt), dando um sentido antropocêntrico a este espaço público já que é o humano que confere um novo sentido ao espaço público praça Roosevelt. 


\section{Mudança de atos: O medo sai de cena para dar lugar à cultura}

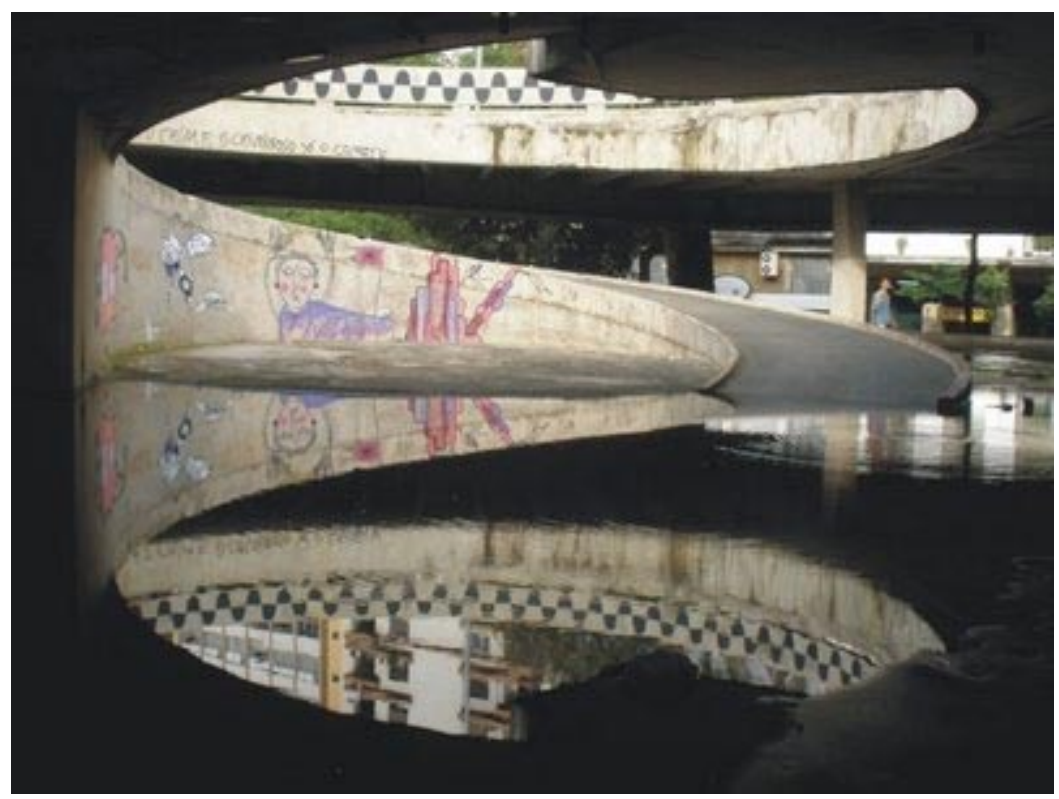

Imagem disponível em: antoniogoper.blogspot

\section{Panorama do palco}

"No início dos anos 1990, a praça Roosevelt era um lugar muito barra pesada”, quem diz isso é Phedra D. Córdoba, atriz integrante da companhia de teatro 'Os Satyros'. Phedra fala com a autoridade de quem já morou e trabalho na Roosevelt. Em entrevista realizada em 2004 para o trabalho para conclusão de curso "A História e as Relações Sociais na Praça Roosevelt" (Universidade Cruzeiro do Sul, São Paulo, 2005), a atriz relatou sua história e como esta se encontrou com a da praça.

$\mathrm{Na}$ década de 1990 a praça era realmente território fértil para o crime. Com uma arquitetura árida, galerias e calçadas mal iluminadas e servindo de viaduto para uma via expressa, local de passagem para a população que ia e vinha do trabalho diariamente, a Roosevelt logo se viu tomada de assalto pelos traficantes de drogas.

Local público por excelência, a praça deveria ser um lugar de convívio social e prática da civilidade, como era na década de 1960. Mas para isso, seria preciso que a população reconhecesse ali um espaço adequado para o encontro, a vivência pública e para a prática da civilidade. Portanto, para ser um espaço público, a praça Rosevelt deveria ser significada como tal pela população da cidade.

Nas palavras de Lucrécia D’Aléssio Ferrara: 
"O significado é uma resultante do modo de representação, é consequência e vem embutido no próprio modo de representação [...] Os textos não verbais não se impõem à observação, mas estão incorporados à realidade." (FERRARA, 1986: 07-18)

Em meados da década de 1990, reconhecer a Roosevelt como equipamento de lazer não era possível. $O$ abandono e decadência do centro da cidade, a insegurança sentida pelos transeuntes quando passavam por ali, a arquitetura que acabou se tornando terreno fértil para a marginalidade e a falta de equipamentos culturais acessíveis a todos, somados ao desinteresse público no tocante a políticas públicas urbanas e culturais, acabou por afastar os paulistanos da praça, tornando-a espaço para a prática de crimes e consequentemente destituindo-a do papel de promoção do encontro e do convívio.

A construção do pentágono somada a crescente preocupação com a segurança, acabou por reconfigurar o papel do que era a praça da Consolação na cidade de São Paulo. De lugar de convívio público, onde a boêmia e os interessados em expressões artísticas encontravam-se, o lugar passou a ser um "lugar êmico".

Na obra "Modernidade Líquida" (Jorge Zahar Editora, Rio de Janeiro,2001), Zygmunt Bauman define 'lugar êmico' como um espaço cujo único destino é ser atravessado e deixado para trás. Contudo, o teórico atenta para a necessidade de acrescentar a este conceito a ideia de 'não lugar', de Georges Benko e Marc Augé, como um espaço enfaticamente público, mas não civil. Segundo o sociólogo, estes são espaços que desencorajam a ideia de estabelecer-se, tornando sua colonização ou domesticação quase impossível.

Bauman vai mais fundo ao dizer:

\footnotetext{
"Um não lugar é" um espaço destituído das expressões simbólicas e de identidade, relações e históricas [...]. Os não lugares não requerem domínio da sofisticada e difícil arte da civilidade." (BAUMAN, 2001: 120)
}

Ora, se esta era a leitura da população em relação à praça Roosevelt, isso devese a contextualização sócio-cultural da época. Lucrécia D’Aléssio Ferrara, em seu "Leitura sem Palavras" (Editora Ática, São Paulo, 1986), esclarece que o significado do espaço urbano e seus equipamentos é definido em grande parte pela leitura 'não verbal' dos habitantes da cidade em relação a este espaço/equipamento.

Para ela, a contextualização é um aspecto decisivo, pois é quem confere a qualificação do espaço e sua consequente identificação social, econômica e cultural. Em "Leitura sem Palvaras", Lucrécia diz:

"A contextualização é responsável pelo uso dos lugares urbanos: uma outra informação que 
redesenha a tridimensionalidade espacial dando-lhe uma outra variável, mais dinâmica e significativa, porque capaz de informar mais rapidamente sobre constituintes espaciais não previstos em projetos de urbanização e, no entanto, capazes d produzir e/ou alterar a imagem de uma rua, avenida ou praça." (FERRARA, 1986: 21)

Distante daquilo que representava para a cidade nos anos 1960, o espaço ocupado pela praça Roosevelt teve seu papel social ressignificado em grande parte graças à sua nova arquitetura. A edificação do pentágono, com suas galerias e sua posterior falta de iluminação contribui para o crescimento de atos criminosos, como assaltos, consumo e a venda de drogas foi decisivo para redimensionar seu papel perante o público da cidade de São Paulo.

A construção da estrutura de concreto destruiu a praça da Consolação - lugar de convívio, lazer e encontros, cuja leitura já estava registrada na memória dos habitantes da cidade - para fazer nascer a praça Franklin Roosevelt, um novo lugar para o qual os paulistanos teriam de olhar, ocupar e dar um significado. $\mathrm{O}$ contexto social da época acabou tornando o novo equipamento público em um 'lugar êmico' e, posteriormente, um 'não lugar', segundo as definições de Zygmunt Bauman.

Se antes, a praça da Consolação tinha um significado prazeroso para os habitantes de São Paulo, este não foi herdado pela Roosevelt. O novo equipamento público, presente do regime militar ao espaço urbano da maior cidade do País, desencorajava a ideia de estabelecer-se, de encontros e de convivência, sendo apenas uma estrutura a ser atravessada ou circundada para se chegar ao outro lado. Não tinha uma relação histórica com a metrópole. Era preciso dar-lhe um significado, uma identidade. O contexto histórico e a arquitetura da praça Franklin Roosevelt acabaram por determiná-la um 'espaço vazio de significado', tornando-a apenas um viaduto.

Inserida no centro da metrópole, lugar abandonado pelas elites por isso negligenciado pela poder público, a praça Roosevelt, como de praxe em grandes cidades, na qualidade de espaço vazio, passou a ser local de abrigo para pessoas em situação de exclusão social e para aquelas que atuam à margem da sociedade.

A praça Roosevelt passava longe da pujança a qual ela deveria representar quando foi construída. Dramas sociais como menores carentes, moradores de rua, prostituição e crimes como tráfico de drogas, assaltos e furtos fizeram desse espaço o seu lugar. Contribuindo decisivamente para a leitura negativa e seu consequente significado para a cidade. 


\section{A mudança do cenário}

O espaço que parecia condenado viu seu destino mudar através daquilo que fez sua fama décadas atrás: as atividades culturais.

A partir de 1996, a instalação de teatros começa a transformar a praça Roosevelt e seu entorno. Em associação com Dema de Francisco e Roberto Asca, a veterana atriz Dulce Muniz - formada pelo Teatro de Arena, cuja sede está em próxima à praça Roosevelt - abriu o "Studio 184". O lugar onde funciona o teatro de Dulce era antes o "Teatro de Câmara de São Paulo", abertos por Ariela Brasil, Jairo Matos, Bosco Brasil e Ariela Goldman. Os também atores não estavam muito satisfeitos com o retorno dado pelo espaço e acabaram cedendo o prédio à Dulce, que costumava utilizálo para ensaiar suas peças. Empenhada em fazer da praça um lugar onde as pessoas pudessem ter acesso às artes, Dulce associou-se à Ação Local Praça Roosevelt para tentar reverter o caráter inóspito do lugar. Mas não houve muitos avanços.

Algumas outras companhias instalaram-se ali, mas foi com a chegada de "Os Satyros" que a praça teve seu caráter reconfigurado no contexto social da cidade.

Fundada por Ivam Cabral e Rodolfo García Vazquez, a companhia Os Satyros tomou lugar onde antes da decadência da praça funcionava um restaurante badalado. O motivo da escolha do espaço foi o preço - bastante acessível - e a adequação a proposta do grupo. Nos fundos, havia um ambiente facilmente remanejado e, na frente, um espaço destino a um bar.

Segundo Ivam e Rodolfo, a chegada do grupo provocou desconfiança entre os moradores da praça, já acostumados ao contexto social no qual a Roosevelt se inseria. Ivam conta que a princípio os moradores pensaram se tratar de um prostíbulo. Mesmo depois de identificado com uma placa onde lia-se "Espaço dos Satyros", a desconfiança permanecia.

À semelhança dos teatros anteriormente instalados ali, Os Satyros também enfrentaram dificuldades relacionadas ao abandono da praça, a criminalidade e ao medo institucionalizado da população em ir até à praça Roosevelt. Esta era sem dúvida a principal barreira a ser quebrada para atrair o público às peças.

Para mudar o macro - a imagem da praça perante a cidade - (mesmo que este não fosse o principal objetivo da companhia), Os Satyros associaram-se, mesmo de forma natural, segundo Rodolfo García Vazquez, ao micro - ou seja, às pessoas que ali estavam.

A companhia acabou aproximando-se da população da praça Roosevelt re- 
cebendo essas pessoas para seus espetáculos e posteriormente, incorporando alguns destes personagens e suas histórias sociais à ela própria, caso de Phedra D. Córdoba, hoje integrante da companhia.

Em 2002, Os Satyros "De Profundis". Com texto de Ivam Cabral e direção de Rodolfo García Vazquez, a peça foi inspirada na vida e obra de Oscar Wilde. A montagem conseguiu destaque nos mais importantes jornais de São Paulo, chamando atenção para o degradado espaço da praça Roosevelt. "De Profundis" ficou em cartaz por um ano.

O teatro na praça Roosevelt passou a chamar a atenção da imprensa para este espaço urbano, suscitando a mudança da imagem e do caráter deste lugar 'não lugar' diante do público paulistano.

O jornalista Valmir Santos, um dos primeiros a noticiar a praça em reportagem co-assinada por Janaina Fidalgo, revela em entrevista concedia em 2005 para o trabalho de conclusão de curso "A História e as Relações Sociais na Praça Roosevelt" (Universidade Cruzeiro do Sul, São Paulo, 2005) que em sua visão a dinâmica dos acontecimentos que conseguiram mudar a cara da praça Roosevelt identifica um movimento no qual o artista se aproxima do espaço e constrói ali uma estética que leva em conta a condição de margem, as divisões de classe e o recrudescimento da violência física e simbólica na sociedade paulistana. Valmir vê nos espetáculos da Roosevelt o teatro da desmaterialização, da essencialidade do trabalho do intérprete. Para ele, ali se faz o teatro da adesão, da diversidade de linguagem, do encontro das diferenças, fazendo surgir uma mudança de códigos que aos poucos tornam-se cotidiana.

A atividade cultural que tomava conta da praça sem precisar expulsar dali quem ali já estava, associada a divulgação da imprensa, acabaram por chamar a atenção da população e do poder público para aquele espaço. Assim, a cidade de São Paulo enxergou um novo contexto social na Roosevelt determinada pela atuação dos teatros.

\section{Considerações finais}

Com a instalação de teatros em seu entorno, a praça Roosevelt ganhou um novo significado, determinante para conferir-lhe um novo uso. Ainda em "Leitura sem Palavras", Lucrécia afirma:

\footnotetext{
"É esse uso que qualifica nossa memória urbana e sedimenta a vida de uma cidade. Alimenta uma tradição, ao mesmo tempo que estimula a dinâmica de sua mudança; os índices referenciais de um uso mantêm-se atualizados e, paradoxalmente, conservam a memória do seu passado." (FERRARA, 1986: 21)
}

Atuando como agente cultural, cujo princípio básico, segundo Teixeira Coelho 
em seu "Usos da Cultura - políticas de ação cultural" (1986, p. 11), é a intervenção sócio-cultural, o teatro mudou a praça Roosevelt e seu entorno, fazendo do 'lugar êmico/não lugar' um espaço onde a civilidade pode ser exercida.

Assim, as atividades culturais desenvolvidas pelos grupos teatrais tiveram um propósito social neste espaço urbano. Mesmo não sendo este o principal objetivo das companhias teatrais que instalaram-se ali, elas foram instrumento para o estabelecimento de uma nova dinâmica neste espaço urbano. Sobre isso, Teixeira Coelho alerta:

\footnotetext{
"A ação, inversamente, não tem começo e não tem fim nitidamente demarcados e não deixa atrás de si produtos formais acabados. O que pode deixar é uma nova cadeia de ações, cujo controle seu autor não consegue assumir e cujo resultado final escapa a qualquer previsão precisa." (COELHO NETO, 1986: 100)
}

Se as companhias teatrais foram o catalisador da mudança na praça Roosevelt, a população que frequenta a praça de São Paulo foi decisiva nesta mutação pois reagiu de forma positiva aos novos acontecimento. $\mathrm{O}$ papel da população nesta dinâmica deve ser destacado pois:

\footnotetext{
"A ação é algo que se faz com, ao lado de, por dentro, desde a raiz - um processo que só tem sujeitos. (...) A ação, contrariamente é a contínua descoberta, o reexame constante, a reelaboração: a vida. (...) A ação cultural é uma aposta conjunta. Aposta-se que o grupo se descobrirá, descobrirá seus fins e seus meios." (COELHO NETO, 1986: 100)
}

Assim, o teatro foi posto para fora, foi expandindo-se em direção ao espaço público. As mesas do bar do "Espaço dos Satyros" tomaram conta da calçada, denotando uma nova ocupação naquele espaço público.

Com a aproximação dos personagens sociais ali presentes, o grupo foi percebendo a riqueza das histórias abrigadas pela Roosevelt. Surgem assim "Transex", escrita por Rodolfo García Vázquez, sobre a vida de três travestis moradores da praça; e "A Vida na Praça Roosevelt", da dramaturga alemã Déa Loher, onde a solidão dos moradores das grandes metrópoles é representada alidindo a aridez de suas construções que, ao contrário de gerarem encontros positivos entre estranhos e promoverem a civilidade, causam justamente o contrário: o afastamento e o estranhamento, cujo principal resultado é o medo do que não é igual.

A simbiose entre praça Roosevelt e companhia "Os Satyros" foi sem dúvida frutífera. Atuando como agitador cultural deste espaço público, o grupo com a expandiu-se na praça. Além de abrir "Espaço dos Satyros 2", o grupo promove a "Satyrianas". O evento anual promove 24 horas ininterruptas de teatro e invenções artísticas na praça, gerando curiosidade nos transeuntes e atraindo para a praça Roosevelt um público que costuma frequentar "ilhas culturais" como a Sala São Paulo. 
A dinâmica atual da praça Roosevelt é uma constatação do que diz Bauman em "Modernidade Líquida":

\begin{abstract}
"A capacidade de conviver com a diferença, sem falar na capacidade de gostar dessa vida e beneficiar-se dela, não é fácil de adquirir e não se faz sozinha. Essa capacidade é uma arte que, como toda arte, requer estudo e exercício. A incapacidade de enfrentar a pluralidade de seres humanos e as ambivalências de todas as decisões classificatórias, ao contrário, se autoperpetuam e reforçam: quanto mais eficazes a tendência à homogeneidade e o esforço para eliminar a diferença, tanto mais difícil sentir-se à vontade em presença de estranhos e tanto mais intensa a ansiedade que ela gera." (BAUMAN, 2001: 123)
\end{abstract}

Hoje a praça Roosevelt não tem mais galerias. Jovens skatistas tomaram conta do espaço para praticar ali seu esporte. Seu entorno está tomado por teatros, sebos, livrarias e bares, onde é possível conversar com as mais diferentes pessoas, desde a platéia, a dramaturgos, escritores, atores, músicos, homens, mulheres, travestis e homossexuais. Pessoas que, a semelhança dos demais habitantes da metrópole, têm vivências e histórias de vida distintas. Isso significa que a praça tornou-se novamente um lugar onde antes e acima de tudo, as pessoas possam compartilhar como personae públicas - sem serem investigadas, pressionadas ou induzidas a tirar as máscaras e "deixar-se ir", "expressar-se".

\title{
Referências bibliográficas
}

BAUMAN, Zygmunt. "Modernidade Líquida". Trad. de Plínio Dentzier. Rio de Janeiro: Jorge Zahar Editora, 2001.

COELHO NETO, José Teixeira. "Usos da Cultura: políticas públicas de ação cultural". Rio de Janeiro: Paz e Terra, 1986.

FERRARA, Lucrécia D’Aléssio. "Leitura sem Palavras”. São Paulo: Editora Ática, 1986.

CARDOSO, Celina. “A História e as Relações Sociais na Praça Roosevelt”. Trabalho de conclusão de curso de Comunicação Social - Habilitação em Jornalismo, São Paulo: Universidade Cruzeira do Sul, 2005.

LIMEIRA, Ana Cristina Medina. "Dominação e Apropriação na Configuração do Espaço em São Bernardo do Campo". Trabalho de conclusão do curso de Gestão de Projetos Culturais e Organização de Eventos, São Paulo: Celacc - ECA/USP, 2008. 